Produto \& Produção, vol. 10, n. 2, p. 01 - 27, jun. 2009

\title{
Aprimorando Produtos Orientados ao Consumidor Utilizando Desdobramento da Função Qualidade (QFD) e Previsão de Demanda
}

\author{
Michel J. Anzanello \\ Mestre em Engenharia de Produção \\ Rutgers - The State University of New Jersey \\ Fernando de Oliveira Lemos \\ Mestre em Engenharia de Produção \\ Pontifícia Universidade Católica do Rio Grande do Sul (PUCRS) \\ Márcia Elisa Echeveste \\ Doutora em Engenharia de Produção \\ Universidade Federal do Rio Grande do Sul (UFRGS)
}

\begin{abstract}
RESUMO
O Desdobramento da Função Qualidade (QFD - Quality Function Deployment) tem sido amplamente utilizado para a conversão das exigências/perspectivas dos clientes em especificações de produto, processo e serviços. Uma das restrições para atender a essas exigências ocorre quando o sistema produtivo não dispõe da capacidade necessária para a implementação dessas melhorias. Na abordagem tradicional, a priorização das exigências/perspectivas e a previsão de demanda são analisadas de forma independente. Este artigo apresenta o desdobramento detalhado das matrizes do QFD e as integra a modelos de previsão de demanda para o aprimoramento de um produto do setor alimentício. Visa-se incorporar ao produto modificações baseadas nas exigências do consumidor e promover ajustes na capacidade produtiva frente à demanda projetada. Como resultado prático, gerou-se um plano de melhoria dos procedimentos e recursos necessários à implementação das demandas priorizadas.
\end{abstract}

Palavras chave: QFD. Previsão de Demanda. Alimentos. 


\section{INTRODUÇÃO}

A busca por vantagens competitivas com o intuito de conquistar clientes constituise em ação de fundamental importância para sobrevivência das empresas em um mercado caracterizado pela constante evolução. Entende-se que a qualidade, dentre as vantagens competitivas, ocupa uma posição diferenciada por estar intimamente relacionada às necessidades dos clientes e afetar os demais aspectos de desempenho (DE RON, 1998; HANSEN, 2001).

O conceito de qualidade, no entanto, evoluiu dos tradicionais patamares oferecidos pelo fornecedor de um serviço ou produto para os elevados níveis exigidos pelo cliente. De tal forma, procura-se inserir o conceito de qualidade na concepção de novos produtos e serviços, incorporando no projeto as demandas e necessidades descobertas como oportunidades. Em geral, tais oportunidades são flagradas por meio de pesquisas de mercado e estudos de comportamento do consumidor (KOTLER, 1991). As pesquisas, quando bem conduzidas, trazem idéias que podem ser convertidas em requisitos e especificações de produtos.

Dentre os diversos métodos existentes para a análise das demandas dos consumidores, destacam-se as matrizes do QFD (Quality Function Deployment). O QFD é um método que promove a conversão destas demandas em requisitos técnicos apropriados para cada estágio de desenvolvimento e fabricação de um novo produto, constituindo-se ainda em importante meio para o aprimoramento de produtos já existentes (AKAO, 1992; SULIVAN, 1996; RIBEIRO et al. 2001).

As prioridades geradas pelo QFD, no entanto, podem colidir com limitações da empresa em oferecer os recursos produtivos necessários para a sua operacionalização. Uma restrição de capacidade produtiva (maquinário e mão-de-obra, entre outros) é um exemplo dessa situação, especialmente em produtos sazonais não estocáveis ou quando os mesmos recursos são compartilhados por itens distintos.

Este estudo reporta a aplicação do QFD vinculada a ferramentas de previsão de demanda com vistas ao aprimoramento de um produto alimentício caracterizado pela dependência da percepção do cliente. A integração aqui proposta permite avaliar os efeitos das melhorias sugeridas pelo QFD (em termos de requisitos e especificações) na capacidade produtiva de atendimento de demandas futuras, ou seja, integra-se uma análise de demanda futura, capacidade produtiva disponível e requisitos de produto e processo. Outra contribuição vem da adaptação nos índices das matrizes do QFD visando a inclusão de aspectos de demanda futura.

A relevância do estudo e sua contribuição para as áreas de Controle da Qualidade e Desenvolvimento de Produto residem em três pontos: (i) integração de duas ferramentas consagradas da Engenharia de Produção (QFD e previsão de demanda), com ênfase à descrição detalhada das etapas constituintes do QFD; (ii) apresentação de um caso real do setor de alimentos em que se busca converter a percepção do consumidor em parâmetros mensuráveis a serem aplicados no processo produtivo; e (iii) elaboração de um plano de melhorias para um produto já existente baseado nas diretrizes do QFD. 
O restante do artigo é organizado como segue. O referencial teórico sobre QFD e previsão de demanda é apresentado na Seção 2. A metodologia é descrita em conjunto com o estudo de caso na Seção 3, enquanto que a Seção 4 traz, de forma sucinta, o plano de melhorias elaborado a partir dos resultados da metodologia. Uma conclusão encerra o estudo na Seção 5.

\section{REFERENCIAL TEÓRICO}

\subsection{Quality Function Deployment - QFD}

O QFD foi originalmente desenvolvido para a obtenção de produtos de alta qualidade, de maneira a satisfazer ou ultrapassar as expectativas dos consumidores. Para tanto, tal metodologia é focada na coleta e análise da "voz do cliente", e posterior equilíbrio das necessidades dos clientes com as potencialidades da empresa (CHAN e WU, 2005). Este processo é capaz de revelar informações relevantes do produto ou serviço de forma sistemática, eliminando a tomada de decisões meramente intuitivas (GOVERS, 1996, 2001; BENNER et al., 2003).

O uso do QFD permite a obtenção de índices de priorização que incorporam tanto requisitos de mercado quanto requisitos técnicos. Os requisitos de mercado englobam a qualidade demandada pelos clientes, enquanto que os requisitos técnicos referem-se à estrutura do produto e do processo. Adicionalmente, o QFD possibilita determinar as áreas a serem priorizadas no melhoramento do produto e processo, visando à redução de custos e aumento do potencial de customização do produto (LOWE et al., 2000; FOGLIATTO et al., 2001; Da SILVEIRA et al., 2001).

Estruturalmente, o QFD é constituído de uma série de matrizes inter-relacionadas, fazendo com que a informação gerada por uma matriz, em geral, constitua-se na entrada da matriz subseqüente ou das matrizes posteriores. O modelo proposto por Akao (1992) contempla 27 matrizes e foi desenvolvido inicialmente para a indústria automobilística, sendo posteriormente simplificado e resumido em quatro matrizes principais (passando a ser referenciado como modelo de ASI - American Supplier Institute): (i) matriz da qualidade, (ii) matriz do produto, (iii) matriz dos processos, e (iv) matrizes dos recursos. Esse modelo tem como premissa o desenvolvimento de um produto ou serviço tomando como base as demandas da qualidade provenientes de pesquisas junto ao consumidor.

Baseado no modelo de Akao, Ribeiro et al. (2001) estabeleceram uma forma diferenciada de sistematização e priorização das características de qualidade ao longo das matrizes. O modelo tem como contribuição a proposta de índices de priorização gerados ao final de cada matriz.

Dentre as diversas utilizações do QFD, merecem destaque aplicações pioneiras nas áreas de desenvolvimento de produto, gerenciamento da qualidade e análise de requisitos de clientes.

Posteriormente, o QFD se expandiu para áreas de projeto, planejamento, tomadas de decisões, engenharia, reengenharia, formação de times de trabalho e avaliações de custos (JAGDEV et al., 1997; DIKMEN et al., 2005). Por conta de sua versatilidade, o 
QFD tem sido amplamente integrado a outras ferramentas de produção. Pramod et al. (2006) sugeriram a combinação de QFD e TPM (Total Preventive Maintenance) para o aprimoramento dos procedimentos de manutenção automotiva, enquanto que $\mathrm{Ni}$ et al.(2007) propuseram a integração de QFD e ferramentas de data mining para a seleção de fornecedores em ambientes caracterizados por elevada customização. Sakao (2007) promoveu modificações no tradicional QFD e sua integração a duas ferramentas de desenvolvimento de produto, com vistas à concepção de processos com reduzido impacto ecológico. Kwong et al. (2007) desenvolveram uma metodologia baseada em lógica fuzzy para a definição das características de processo a serem priorizadas pelo QFD, além de permitir uma melhor avaliação das correlações existentes entre tais características.

Em termos de suas limitações, Poel (2007) descreve problemas metodológicos do QFD, entre eles a dificuldade de incorporar ao produto/processo demandas coletivas sem violar restrições de produção inicialmente estabelecidas. Hari et al. (2007) apontam limitações do QFD quando utilizado em sistemas complexos e sugerem modificações na tradicional estrutura para aplicações desta natureza.

O QFD normalmente é utilizado para identificar e priorizar melhorias em produtos considerando demandas estáveis, situação em que há o aproveitamento da capacidade produtiva existente. Quando o produto apresenta variação em termos de demanda, verifica-se a necessidade de ajustes nas matrizes do QFD. Por essa razão, este artigo inclui o conhecimento de previsão de demandas ao QFD, propondo uma reorganização das matrizes que o constituem.

\subsection{Previsão de Demanda}

A previsão de demanda é uma estimativa da demanda futura de um produto ou serviço sobre certas condições conjecturais (MOON et al., 1998). Previsões de demanda acuradas auxiliam no desenvolvimento de estratégias, alocação de recursos e identificação de prioridades (THOMAS, 1987; LYNN; SCHNAARS; SKOV, 1999), além de permitir, pela operacionalização eficiente da produção e serviços, que as organizações ofereçam elevados níveis de serviço aos clientes, planejem expansões de capacidade e evitem perdas nas vendas e estoques (KOTLER, 1991; MOON et al. 1998; KAHN, 2002). As previsões de demanda servem como um guia para a política de decisões de médio e longo prazo, sendo também aplicadas no monitoramento do desempenho de sistemas através de previsões freqüentes de curto prazo (LINDBERG; ZACKRISSON, 1991).

Os métodos que geram as previsões de demanda são classificados em métodos quantitativos e qualitativos (MONTGOMERY; JOHNSON; GARDINER, 1990; LEMOS, 2006). Métodos quantitativos são baseados na caracterização da estrutura de séries temporais históricas e na previsão de eventos futuros baseada naquela estrutura (SPEDDING; CHAN, 2000), ao passo que métodos qualitativos envolvem estimações subjetivas através da opinião de especialistas ou consumidores. Apesar dos métodos qualitativos compreenderem técnicas estruturadas, como, por exemplo, Pesquisas de Intenções e Delphi, o processo para obter a previsão é subjetivo (MONTGOMERY; JOHNSON; GARDINER, 1990). 
Métodos quantitativos são classificados em métodos de série temporais e métodos causais. Os métodos de séries temporais envolvem a análise estatística de dados passados da variável a ser prevista. Os métodos causais são baseados na análise estatística de realizações passadas de variáveis que são relacionadas à variável de interesse para a previsão (ARCHER, 1980). Os métodos de séries temporais se dividem em (MENTZER; GOMES, 1989): (i) métodos com modelos matemáticos fixos (FMTS - fixed-model time series); e (ii) métodos com modelos matemáticos ajustáveis ou abertos (OMTS - open-model time series).

Os métodos FMTS fundamentam-se em equações fixas e utilizadas sob considerações que certos componentes do padrão de demanda existem ou não na série temporal, sendo os métodos de Média Móvel e de Suavização Exponencial exemplos de FMTS. Métodos OMTS desenvolvem um modelo de previsão depois de identificar os componentes existentes nas séries históricas de demanda, sendo o método de Box-Jenkins um exemplo deste método (MENTZER; COX, 1984; MENTZER; GOMES, 1989).

Análises subjetivas devem ser integradas ao processo preditivo quando os métodos quantitativos não são capazes de agregar aos modelos matemáticos mudanças internas e externas ao ambiente organizacional; ou seja, para situações novas, para sistemas com dados heterogêneos, para previsões de longo prazo e para situações em que há dúvida sobre qual método é mais preciso (GOODWIN, 2000; ARMSTRONG, 2001). A aplicação de uma análise subjetiva ao processo de previsão deve ser feita de uma maneira estruturada, pela utilização de métodos qualitativos. Estes métodos são freqüentemente usados para previsões de médio e longo prazo, ou relativas a novas situações com dados limitados e nenhum precedente histórico (CHAMBERS; MULLICK; SMITH, 1971; GEORGOFF; MURDICK, 1986).

Os métodos qualitativos incorporam uma grande quantidade de conhecimento no processo de previsão e adicionam consenso à previsão (SANDERS; MANRODT, 1994; GOODWIN, 2002). As previsões de métodos qualitativos são resultados da opinião de entrevistados (por exemplo, clientes) ou da opinião de especialistas (ELSAYED; BOUCHER, 1994).

O método de Estimativa da Força de Vendas é popular nas organizações devido ao fato da proximidade dos colaboradores do setor de vendas com clientes e presumidamente em uma posição com conhecimento de futuras mudanças no mercado (WINKLHOFER; DIAMANTOPOULOS). As estimativas dos especialistas são baseadas no julgamento, intuição, pesquisas, técnicas comparativas, conhecimento técnico, conhecimento sobre análise de dados e procedimentos de previsão, e/ou no conhecimento de relações de causa e efeito entre variáveis adquirido com a experiência em processos preditivos nas organizações (WEBBY; O'CONNOR, 1996). Os especialistas também podem usar métodos quantitativos para analisar séries temporais históricas antes de usá-las como dados de entrada do método qualitativo (WRIGHT; LAWRENCE; COLLOPY, 1996).

As previsões obtidas por métodos qualitativos podem ser baseadas em conhecimento contextual (experiência do especialista na indústria; familiaridade com os produtos/serviços a serem previstos; conhecimento do mercado) e/ou conhecimento técnico (conhecimento de métodos de previsão e análise de dados) (WEBBY; O'CONNOR, 1996). Previsões mais acuradas são obtidas pela integração de métodos 
quantitativos com previsões qualitativas baseadas em conhecimento contextual do que as baseadas em conhecimento técnico (SANDERS; RITZMAN, 1995).

Diversos estudos apresentam evidências de que a integração, de métodos qualitativos e quantitativos em especial, é a melhor abordagem para a obtenção de previsões mais acuradas (RINGUEST; TANG, 1987; CLEMEN, 1989; BLATTBERG; $\mathrm{HOCH}$, 1990) pela incorporação do conhecimento contextual nos processos matemáticos de previsão (WRIGHT; LAWRENCE; COLLOPY, 1996).

Em particular, no desenvolvimento de novos produtos e melhorias nos já existentes, a previsão da demanda é fator fundamental na escolha e implementação de melhorias. Isto significa que o uso de uma ferramenta voltada ao planejamento da qualidade, como o QFD, pode demonstrar uma das dimensões do produto. Outra dimensão a ser considerada é a previsão da demanda, a qual auxilia na avaliação conjunta da capacidade produtiva para desenvolvimento destas melhorias, ampliando a visão da equipe de desenvolvimento de produto.

\section{DESCRIÇÃO DA METODOLOGIA E ESTUDO DE CASO}

A metodologia proposta visa integrar as matrizes do QFD (seguindo a sistemática proposta por Ribeiro et al., 2001) a ferramentas de previsão de demanda. O objetivo principal é apresentar uma metodologia para operacionalizar a incorporação dos requisitos dos clientes ao produto e processo produtivo de forma precisa (baseado nas diretrizes do QFD), garantindo a existência dos recursos produtivos necessários à execução daqueles requisitos com base na demanda futura do produto. A representação do método proposto é apresentada na Figura 1, e descrito em detalhes na seqüência. Para uma maior clareza, a metodologia é apresentada em paralelo ao estudo de caso.

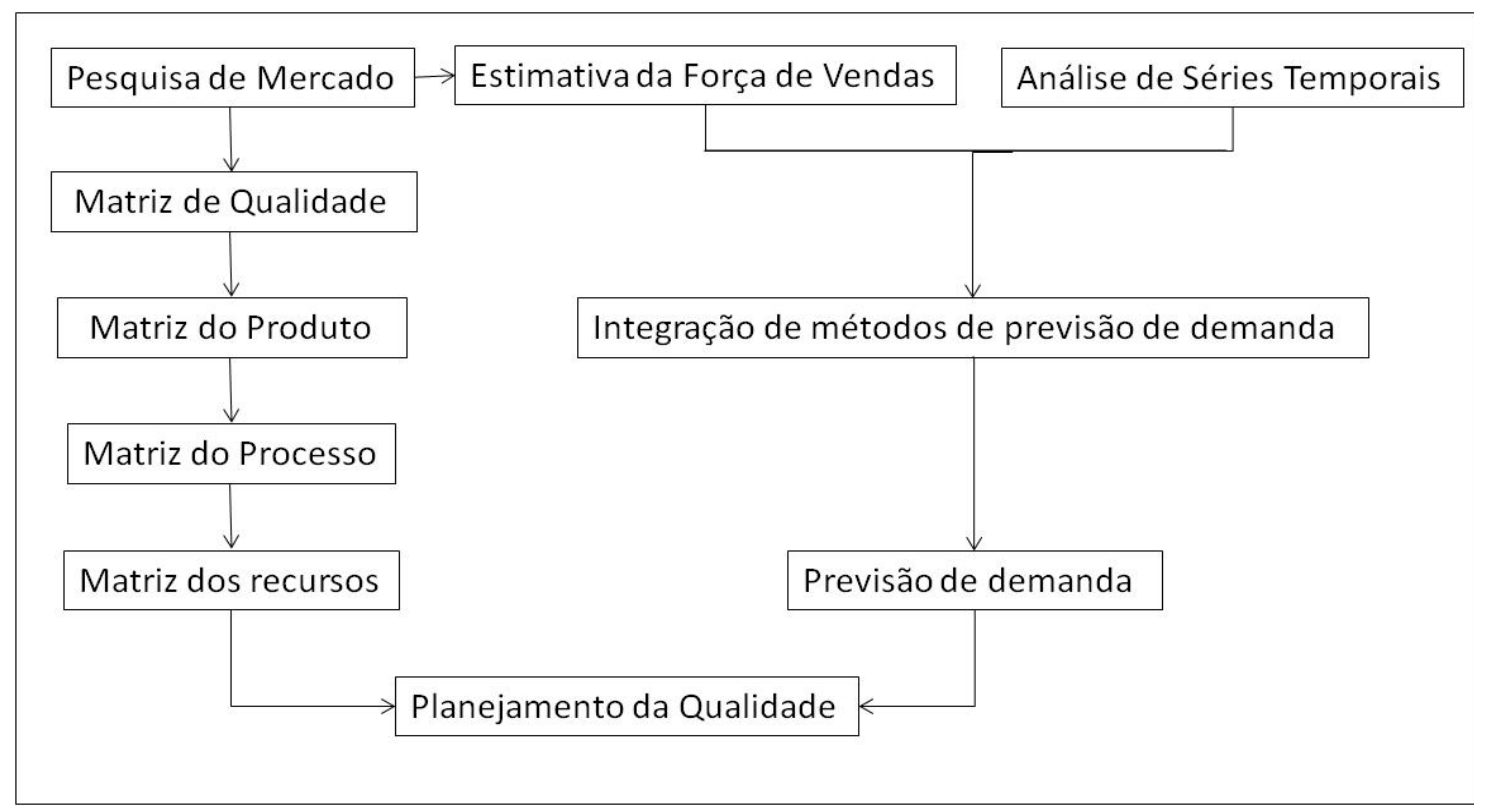

Figura 1 - Representação do método proposto. 
A metodologia proposta foi aplicada no processo de produção de Peru Natalino em uma empresa de grande porte do setor alimentício. A aplicação do QFD encontrou suporte nas seguintes deficiências do setor responsável pela produção da ave: (i) ausência de uma metodologia eficiente para definição dos requisitos de qualidade de produtos já existentes; (ii) inexistência de pesquisas de mercado; e (iii) carência de um procedimento estruturado de conversão das necessidades dos consumidores em parâmetros de produção e qualidade. Inicialmente, para identificação e priorização das demandas, uma pesquisa de mercado foi conduzida.

\subsection{Pesquisa de Mercado}

A pesquisa de mercado tem como objetivo revelar e priorizar as demandas da qualidade, servindo como ponto de partida para o desdobramento da mesma. Ao conduzir pesquisas em populações com demandas diferenciadas, inicialmente identificam-se os nichos de mercado representados por estratos de pesquisa. Neste estudo, foram identificadas as seguintes variáveis para estratificação e extração de uma amostra representativa para a população considerada: (i) dois níveis financeiros, formados por clientes incluídos nos segmentos A e B. Segundo entendimento dos pesquisadores, o consumo do produto Peru Natalino é mais pronunciados em consumidores inseridos nestes segmentos; (ii) três faixas etárias (20-35, 36-50 e 5170), assumindo-se preferência do produto por pessoas com certa estabilidade financeira (a qual geralmente está correlacionada com a idade); e (iii) cinco regiões hipotéticas do estado do Rio Grande do Sul, de maneira a verificar a aceitação do produto em comparação aos pratos típicos de final de ano de cada região. As informações provenientes desta variável de estratificação podem ser úteis para adequar características do produto aos consumidores de cada região.

\subsubsection{Tamanho de Amostra e Procedimento Amostral}

A técnica de amostragem aleatória estratificada foi utilizada neste estudo. Para o cálculo do número de agrupamentos, foram utilizadas as duas variáveis de estratificação com maior número de classes: região (5 classes) e faixa etária (3 classes). Para o cálculo do número de questionários por agrupamento, considerou-se um nível de significância moderado $(=0.05)$, um coeficiente de variação moderado $(10 \%)$ e um erro relativo médio (5\%). Detalhes do procedimento de cálculo de amostra são apresentados em Ribeiro et al. (2001).

A distribuição do número de questionários nos estratos foi realizada de forma proporcional ao tamanho dos mesmos, de acordo com a Tabela 1. 
Tabela 1 - Número de questionários por estrato

\begin{tabular}{lccc|ccc} 
& \multicolumn{3}{c|}{ Classe A (30\%) } & \multicolumn{3}{c}{ Classe B (70\%) } \\
\cline { 2 - 7 } & \multicolumn{3}{c|}{ Faixa etária (\% de participação) } & \multicolumn{3}{c}{ Faixa etária (\% de participação) } \\
\hline Região (\% de participação) & $20-35(20 \%)$ & $36-50(50 \%)$ & $51-70(30 \%)$ & $20-35(20 \%)$ & $36-50(50 \%)$ & $51-70(30 \%)$ \\
\hline Região 1 (25\%) & 8 & 9 & 8 & 9 & 21 & 13 \\
Região 2 (30\%) & 8 & 11 & 8 & 11 & 26 & 16 \\
Região 3 (15\%) & 8 & 8 & 8 & 8 & 13 & 8 \\
Região 4 (10\%) & 8 & 8 & 8 & 8 & 9 & 8 \\
Região 5 (20\%) & 8 & 8 & 8 & 8 & 17 & 11 \\
\hline
\end{tabular}

Com base no processo amostral, conduziu-se uma pesquisa em duas etapas: uma fase qualitativa para levantamento das demandas e uma fase quantitativa para priorização destas demandas.

\subsubsection{Pesquisa Qualitativa}

Uma amostra de 310 consumidores do Rio Grande do Sul respondeu a um questionário qualitativo com questões abertas, focado nas principais características percebidas ao mencionarem o produto Peru Natalino. A aplicação dos questionários seguiu a distribuição apresentada na Tabela 1. O questionário qualitativo visa obter informações para elaboração da árvore da qualidade demandada e, posteriormente, na elaboração do questionário fechado. As questões propostas aos clientes são apresentadas abaixo, tendo sido aplicadas por funcionários terceirizados e posicionados próximos aos balcões de produtos congelados de supermercados previamente definidos.

Que características você considera importantes na hora de adquirir o produto Peru Natalino? (listar no mínimo 3 características)

Que motivos fazem com que você deixe de comprar o produto Peru Natalino nas festas de final de ano?

Quais os principais problemas que você encontra no processo de preparo/consumo deste produto?

Você já optou por outro tipo de ave em detrimento ao peru nas festas de final de ano? Por quê?

Os resultados do questionário aberto foram compilados em uma árvore de qualidade demandada, organizada em níveis hierárquicos primário e secundário, sendo tais níveis responsáveis pelo detalhamento da demanda. As respostas obtidas no questionário conduzem aos itens de qualidade demandada pelo cliente (definidos como "nível secundário"), os quais são agrupados por similaridade e consolidam os componentes do nível primário. Esse nível é composto por: (i) aspecto visual agradável, (ii) tamanho adequado da ave, (iii) sabor agradável, e (iv) praticidade no preparo, conforme apresentado no Quadro 1. 
Quadro 1 - Árvore de qualidade demandada

\begin{tabular}{ll}
\hline Nível primário & Nível secundário \\
\hline \multirow{3}{*}{ Bom aspecto visual } & $\begin{array}{l}\text { Boa aparência da embalagem } \\
\text { Informações contidas na embalagem em conformidade com o produto } \\
\text { Boa aparência do produto (carcaça limpa, cor uniforme) } \\
\end{array}$ \\
\hline \multirow{2}{*}{ Pamanho adequado } & $\begin{array}{l}\text { Variedade do tamanho do produto } \\
\text { Maior quantidade de carne branca } \\
\text { Bom rendimento do produto }\end{array}$ \\
\hline \multirow{3}{*}{ Sabor agradável } & Carne tenra e suculenta \\
& $\begin{array}{l}\text { Carne mais saborosa } \\
\text { Variedade de tipos de tempero }\end{array}$ \\
\hline \multirow{2}{*}{ Praticidade de preparo } & $\begin{array}{l}\text { Presença do dispositivo de tempo de cozimento } \\
\text { Praticidade no preparo e/ou consumo }\end{array}$ \\
& Presença de sugestões de receita na embalagem \\
\hline
\end{tabular}

\subsubsection{Pesquisa Quantitativa}

O questionário quantitativo (fechado) foi aplicado a 310 respondentes obedecendo à distribuição da Tabela 1. Esse instrumento de pesquisa foi gerado em concordância com as diretrizes apontadas pelos níveis primário e secundário do questionário aberto. Seu preenchimento objetivou (i) definir a importância conferida pelos consumidores aos itens relacionados ao nível secundário, utilizando-se uma escala de 1 (pouco importante) a 10 (muito importante); e (ii) dispor em ordem decrescente a importância dos itens referentes ao nível primário. $O$ questionário fechado utilizado neste estudo é apresentado no Anexo A.

Os graus de importância atribuídos pelos respondentes aos itens secundários da qualidade demandada são compilados através da média aritmética da importância atribuída e então convertidos em pesos percentuais, dando origem ao Índice de Importância da Qualidade Demandada (IDi). O IDi é posteriormente ajustado pela equipe de desenvolvimento de produtos com base na viabilidade de execução de alterações que conduzam ao resultado demandado pelo cliente, gerando o Índice de Importância Corrigido da Qualidade Demanda (IDi*), apresentado na equação (1). Os fatores de ajuste referem-se à avaliação estratégica (Ei) e competitiva (Mi) em relação à concorrência, e tem como finalidade identificar pontos fortes e pontos defasados do produto em análise em relação ao mercado, tendo por base a escala apresentada na Tabela 2.

$$
I D_{i}^{*}=I D_{i} \times \sqrt{M_{i}} \times \sqrt{E_{i}}
$$


Tabela 2 - Escala de ponderação para os itens de qualidade demandada

\begin{tabular}{cl}
\hline \multicolumn{2}{c}{ Avaliação competitiva $\left(M_{i}\right)$} \\
\hline Escala & \multicolumn{1}{c}{ Descrição } \\
\hline 2,0 & Muito abaixo da concorrência \\
1,5 & Abaixo da concorrência \\
1,0 & Similar à concorrência \\
0,5 & Muito acima da concorrência \\
\hline
\end{tabular}

\begin{tabular}{cl}
\hline \multicolumn{2}{c}{ Avaliação estratégica $\left(E_{i}\right)$} \\
\hline Escala & \multicolumn{1}{c}{ Descrição } \\
\hline 2,0 & Alta importância estratégica \\
1,5 & Importante \\
1,0 & Moderado \\
0,5 & Baixa importância \\
\hline
\end{tabular}

Fonte: Ribeiro et al. (2001)

A ênfase da ponderação está no resultado da avaliação do consumidor (IDi), o qual é ponderado pela avaliação estratégica e competitiva. A raiz do valor da escala garante que o índice IDi seja ponderado entre 0,5 e 2,0, isto é, na hipótese de um item ser muito importante estrategicamente $(2,0)$ e estar muito abaixo da concorrência $(2,0)$, o valor da priorização será duplicado. No caso do outro extremo acontecer (se um item estiver muito acima da concorrência $(0,5)$ e a importância estratégica for mais baixa $(0,5))$, o índice será reduzido em 0,5 . Tal ponderação visa priorizar os itens mais importantes em termos estratégicos e em posição desfavorável quanto à concorrência (RIBEIRO et al., 2001). A priorização dos itens de qualidade demandada para o produto Peru Natalino é apresentada na Figura 2.

\begin{tabular}{|c|c|c|}
\hline $\begin{array}{l}\text { ITENS DE QUALIDADE DEMANDADA } \\
\end{array}$ & IDi* & \\
\hline Carne mais saborosa & 15,1 & \\
\hline Boa aparência do produto & 12,3 & \\
\hline Variedade de tipos de temperos & 11,6 & \\
\hline Carne tenra e suculenta & 10,3 & \\
\hline Carne com boa consistência & 9,6 & \\
\hline Produtos sem partes quebradas ou separadas & 9,5 & 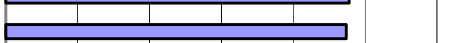 \\
\hline Variedade do tamanho & 8,4 & 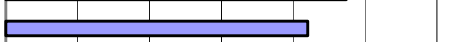 \\
\hline Praticidade no preparo e/ou consumo & 8,3 & 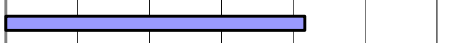 \\
\hline Bom rendimento do produto & 7,8 & 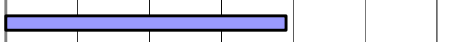 \\
\hline Maior quantidade de carne branca & 7,7 & 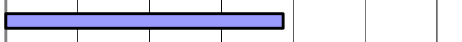 \\
\hline Redução do tempo de cozimento e/ou preparo & 7,3 & $\square$ \\
\hline Boa aparência da embalagem & 7,2 & \\
\hline Inform. na embalagem em conformidade com o produto & 6,1 & 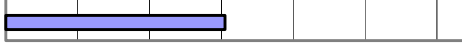 \\
\hline
\end{tabular}

Figura 2 - Priorização da qualidade demandada pelo cliente.

O item de qualidade demandada priorizado é "Carne mais saborosa", seguido por "Boa aparência do produto" e "Variedade de tipos de temperos", demonstrando que os aspectos sensoriais são mais valorizados pelo consumidor.

\subsection{Desdobramento da Qualidade na Manufatura}

Os itens de qualidade demandada pelos clientes (obtidos na Seção 3.1.3) são associados às distintas etapas do processo produtivo (produto, processo e recursos) através das matrizes do QFD, descritas na seqüência. 
Os itens de qualidade demandada são convertidos em parâmetros de processo mensuráveis e objetivos (definidos como Características de Qualidade), utilizando-se escalas sensoriais, percentuais e número de ocorrência dos atributos avaliados. Objetiva-se, com tal transformação, permitir completo entendimento (pelos responsáveis pelo processo) das demandas estabelecidas pelos consumidores. Os resultados são apresentados no Quadro 2.

Quadro 2 - Identificação das características de qualidade

\begin{tabular}{|c|c|}
\hline ITEM DE QUALIDADE DEMANDADA & CARACTERÍSTICA DE QUALIDADE \\
\hline Carne mais saborosa & Teste sensorial (1 a 10) \\
\hline Boa aparência do produto & $\mathrm{N}^{\circ}$ de aves não conformes p/turno (hematomas, coágulos, pele) \\
\hline Variedade de tipos de temperos & No de opções de temperos e \% de injeção de ingredientes/un \\
\hline Carne tenra e suculenta & Percentual de umidade após preparo/unidade \\
\hline Produtos sem partes quebradas ou separadas & Teste sensorial de textura da carne (1 a 10 ) \\
\hline Variedade do tamanho & $\mathrm{N}^{\circ}$ de aves não conformes p/turno (partes quebradas) \\
\hline Praticidade no preparo/consumo & Tempo de criação da ave no campo/lote \\
\hline Maior quantidade de carne branca & Escala de praticidade (1 a 10) \\
\hline Bom rendimento do produto & Percentual de carne branca após desossa do peru/carcaça \\
\hline Redução do tempo de cozimento/preparo & Percentual de carne após desossa do peru/carcaça \\
\hline Boa aparência da embalagem & Tempo médio de cozimento/unidade \\
\hline Inform. na embalagem em conform. com o prod. & $\mathrm{N}^{\circ}$ de embalagens com erro de informações/mês \\
\hline ITEM DE QUALIDADE DEMANDADA & CARACTERÍSTICA DE QUALIDADE \\
\hline Carne mais saborosa & Teste sensorial (1 a 10$)$ \\
\hline Boa aparência do produto & $\mathrm{N}^{\circ}$ de aves não conformes p/turno (hematomas, coágulos, pele) \\
\hline Variedade de tipos de temperos & $\mathrm{N}^{\circ}$ de opções de temperos e \% de injeção de ingredientes/un \\
\hline Carne tenra e suculenta & Percentual de umidade após preparo/unidade \\
\hline Produtos sem partes quebradas ou separadas & Teste sensorial de textura da carne (1 a 10) \\
\hline Variedade do tamanho & $\mathrm{N}^{\circ}$ de aves não conformes p/turno (partes quebradas) \\
\hline Praticidade no preparo/consumo & Tempo de criação da ave no campo/lote \\
\hline Maior quantidade de carne branca & Escala de praticidade (1 a 10) \\
\hline Bom rendimento do produto & Percentual de carne branca após desossa do peru/carcaça \\
\hline Redução do tempo de cozimento/preparo & Percentual de carne após desossa do peru/carcaça \\
\hline Boa aparência da embalagem & Tempo médio de cozimento/unidade \\
\hline Inform. na embalagem em conform. com o prod. & $\mathrm{N}^{\circ}$ de embalagens com erro de informações/mês \\
\hline
\end{tabular}

A Matriz da Qualidade foi gerada posicionando-se as Características de Qualidade nas colunas e os Itens de Qualidade Demandada nas linhas da matriz, conforme esquematizado na Figura 3 . Valores de intensidade de relacionamento são então atribuídos para os cruzamentos das linhas e colunas através da seguinte escala de intensidade: Muito forte (9), Forte (6), Média (3), e Fraca (1). A Matriz da Qualidade gerada para o produto Peru Natalino é apresentada no Anexo B, sendo que alguns valores foram modificados de forma a assegurar sigilo de informações. As matrizes de 
relacionamento geradas nas etapas seguintes seguem os moldes desse mesmo anexo e são suprimidas por limitações de espaço.

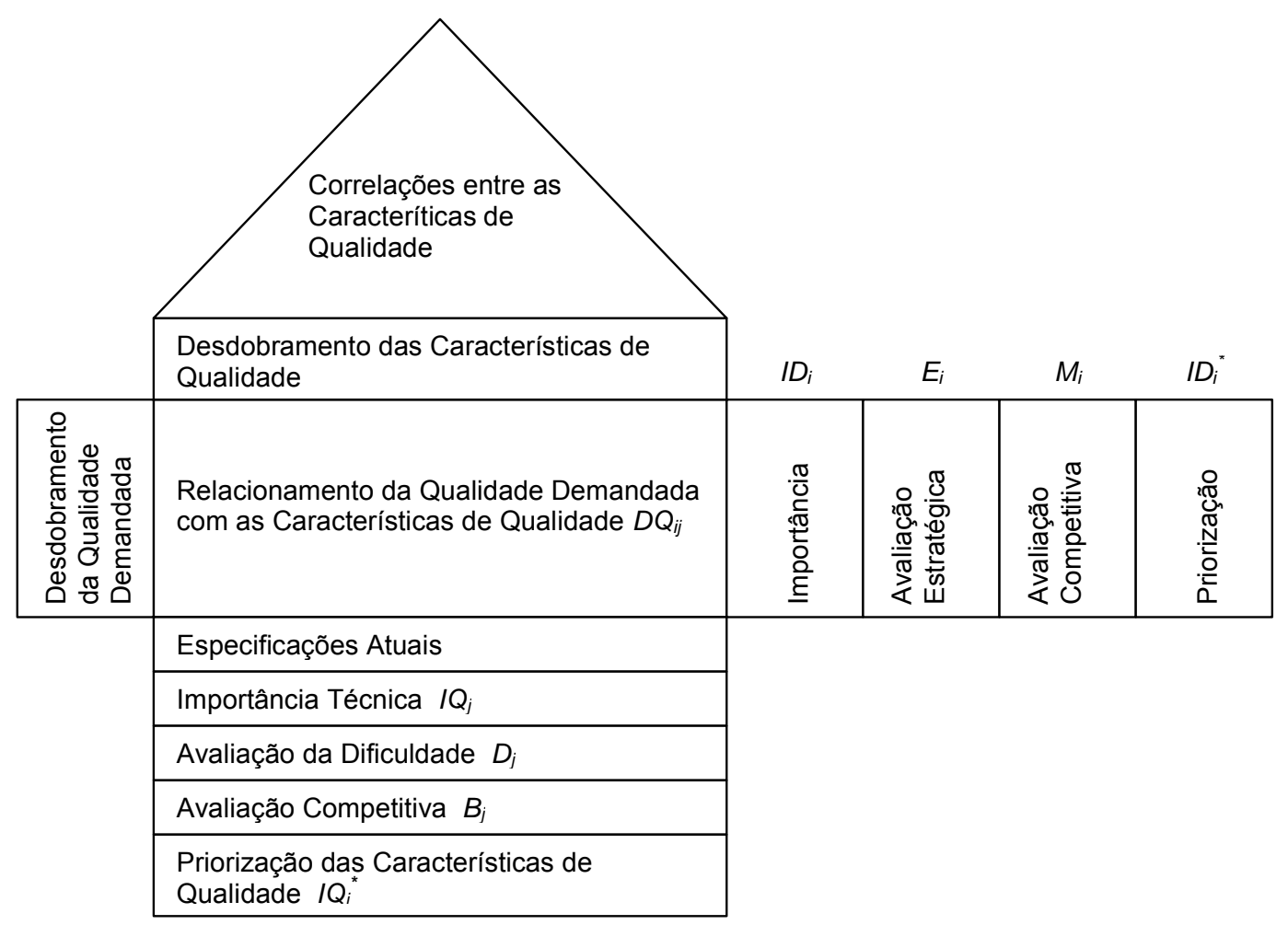

Figura 3 - Organização dos dados na Matriz da Qualidade. Adaptado de Ribeiro et al. (2001)

Os valores de intensidade atribuídos na Matriz da Qualidade apresentada na Figura 3 (DQij) foram relacionados com os valores de IDi* de acordo com a equação (2), gerando a Importância Técnica das Características de Qualidade (IQj). Este índice foi novamente corrigido pela equipe de desenvolvimento com base na dificuldade de atendimento das especificações-meta dos requisitos do produto ( $\mathrm{Dj}$ ) e avaliação competitiva (benchmarking) da posição do produto frente à concorrência $(\mathrm{Bj})$, segundo a escala de ponderação da Tabela 3. Finalmente, a Importância das Características de Qualidade Corrigida (IQj*) é determinada através da equação (3).

$$
\begin{aligned}
I Q_{j} & =\sum_{i=1}^{n} I D_{i}^{*} \times D Q_{i j} \\
I Q_{j}^{*} & =I Q_{j} \times \sqrt{D_{j}} \times \sqrt{B_{j}}
\end{aligned}
$$


Tabela 3 - Escala de ponderação para os itens de qualidade demandada

\begin{tabular}{cl}
\hline \multicolumn{2}{c}{ Avaliação competitiva $\left(B_{i}\right)$} \\
\hline Escala & \multicolumn{1}{c}{ Descrição } \\
\hline 2,0 & Muito abaixo da concorrência \\
1,5 & Abaixo da concorrência \\
1,0 & Similar à concorrência \\
0,5 & Muito acima da concorrência \\
\hline
\end{tabular}

\begin{tabular}{cl}
\hline \multicolumn{2}{c}{ Avaliação da Dificuldade de Atuação $\left(D_{i}\right)$} \\
\hline Escala & \multicolumn{1}{c}{ Descrição } \\
\hline 2,0 & Fácil \\
1,5 & Moderada \\
1,0 & Difícil \\
0,5 & Muito difícil \\
\hline
\end{tabular}

Fonte: Ribeiro et al. (2001)

Os valores de IQj* para o produto Peru Natalino são apresentados na Figura 4. O "Número de opções de tempero" é a característica de qualidade mais importante, seguida pelo "Percentual de injeção de ingredientes/unidade" e pelo "Tempo de criação da ave no campo". A ordem das características de qualidade apresentadas na Figura 4 será o ponto de partida para as próximas fases, permitindo à equipe de desenvolvimento de produtos da empresa optar por uma nova concepção do produto ou identificar as características a serem aprimoradas.

\begin{tabular}{ll}
\hline CARACTERÍSTICAS DE QUALIDADE & IQj* $^{*}$ \\
\hline Número de opções de tempero & 49,7 \\
Percentual de injeção de ingredientes/unidade & 46,9 \\
Tempo de criação da ave no campo/lote & 46,9 \\
Teste sensorial de sabor (1 a 10) & 43,2 \\
Tempo médio de cozimento/unidade & 34,3 \\
\% de aves não conformes p/dia & 31,9 \\
Percentual de umidade após preparo/unidade & 30,3 \\
Escala de satisfação quanto à embalagem (1 a 10) & 26,3 \\
$\mathrm{~N}^{\circ}$ de aves não conformes p/dia (partes quebradas) & 24,0 \\
Teste sensorial de textura da carne (1 a 10) & 23,6 \\
Escala de praticidade de preparo (1 a 10) & 21,9 \\
\% de embalagens com erro de informações/mês & 15,1 \\
\% da carne após desossa do peru/carcaça & 10,0 \\
\% de carne branca após desossa do peru/carcaça & 10,0 \\
\hline
\end{tabular}

Figura 4 - Priorização das características de qualidade.

\subsubsection{Matriz do Produto}

De acordo com o modelo de Ribeiro et al. (2001), a matriz do produto visa fornecer uma medida concreta para avaliar o quanto cada parte do produto está associada à obtenção das características de qualidade anteriormente destacadas, conforme esquema apresentado na Figura 5. O objetivo é priorizar as partes críticas para a qualidade do produto final. 


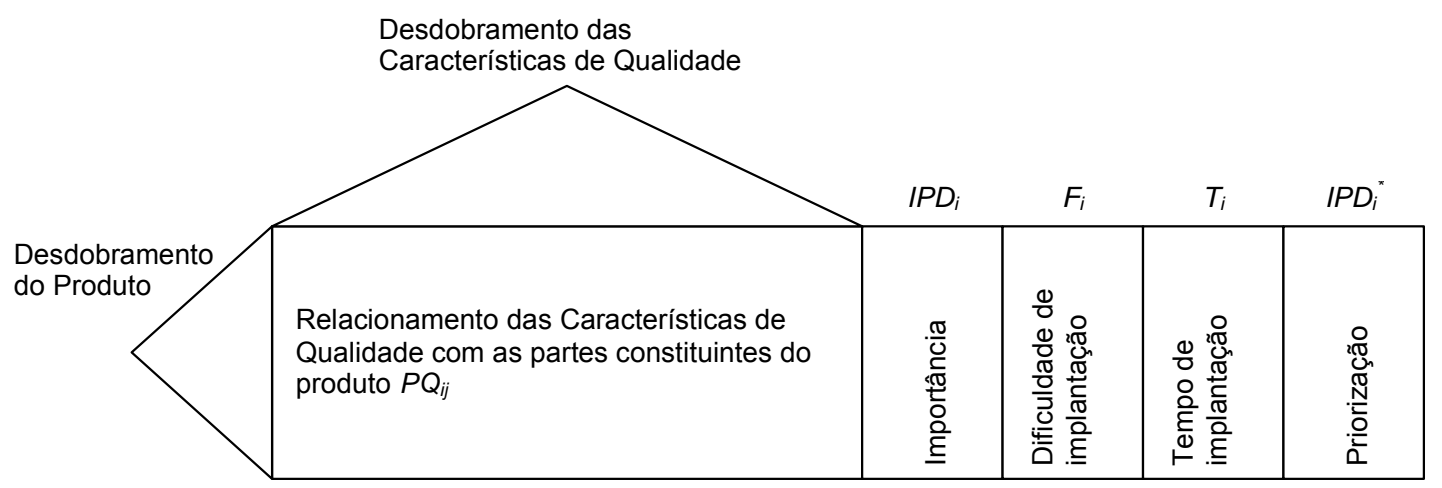

Figura 5 - Organização da Matriz do Produto. Adaptado de Ribeiro et al. (2001)

Nesta etapa, o Peru Natalino foi desdobrado em partes, valendo-se da opinião dos especialistas do processo: (i) peru inteiro, (ii) tempero, e (iii) embalagem. A opção por ave inteira é justificada por constituir-se na forma final de apresentação do produto ao cliente. O levantamento da importância das partes foi realizado de forma análoga à Matriz de Qualidade. Inicialmente atribui-se um valor de intensidade (escala 1-9) associando Partes do Produto (linhas) e Características de Qualidade (colunas), gerando o índice PQij. Na seqüência, cada PQij é multiplicado pelo respectivo IQj* (gerado na Matriz de Qualidade), de acordo com a equação (4).

$$
I P D_{i}=\sum_{j=1}^{n} P Q_{i j} \times I Q_{j}^{*}
$$

O índice resultante é corrigido com base na dificuldade e tempo necessários para implementar modificações nas partes do produto, com base na equação (5) e Tabela 4. É importante enfatizar que aspectos de implantação de melhorias (dificuldade e tempo) são fundamentais para a análise, na medida em que é mais interessante desenvolver prioritariamente aquelas partes que responderão de forma mais rápida às melhorias propostas. Note que, na escolha das partes a serem desenvolvidas, já estão sendo levados em consideração os aspectos de satisfação do cliente, na medida em que a importância das partes é determinada a partir da importância corrigida das características de qualidade.

$$
I P D_{i}^{*}=I P D_{i} \times \sqrt{F_{i}} \times \sqrt{T_{i}}
$$

Tabela 4 - Escala de ponderação para as partes

\begin{tabular}{cl}
\hline \multicolumn{2}{c}{ Dificuldade de implantação $\left(F_{i}\right)$} \\
\hline Escala & \multicolumn{1}{c}{ Descrição } \\
\hline 2,0 & Fácil \\
1,5 & Moderada \\
1,0 & Difícil \\
0,5 & Muito difícil \\
\hline
\end{tabular}

\begin{tabular}{cl}
\hline \multicolumn{2}{c}{ Tempo de implantação $\left(T_{i}\right)$} \\
\hline Escala & \multicolumn{1}{c}{ Descrição } \\
\hline 2,0 & Pequeno \\
1,5 & Moderado \\
1,0 & Grande \\
0,5 & Muito grande \\
\hline
\end{tabular}

Fonte: Ribeiro et al. (2001) 
A Importância de cada Parte Corrigida (IPDi*) é apresentada na Figura 6. Percebese que o tempero figura como a parte do produto a ser priorizada em um plano de melhorias.

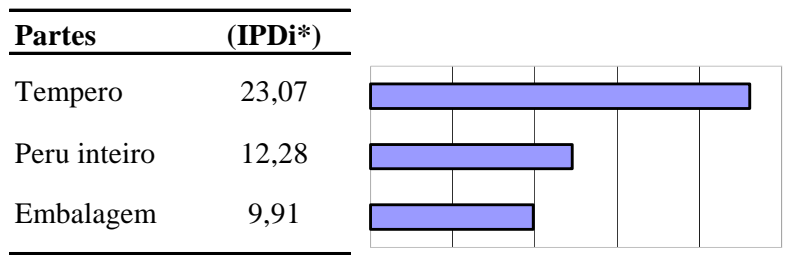

Figura 6 - Priorização das partes do produto.

\subsubsection{Matriz do Produto}

A análise das partes é finalizada através da construção da Matriz das Características das Partes, a qual promove o cruzamento das partes do produto com as características a serem controladas em cada uma dessas partes. Para tanto, utiliza-se novamente a escala de intensidade (1-9) para quantificar a importância da manutenção de cada característica para a adequada obtenção de cada parte. O cruzamento dos valores de intensidade com $0 \mathrm{IPi}^{*}$ de cada parte do Peru Natalino aponta as características das partes a serem priorizadas em um plano de atuação, conforme resultados apresentados na Figura 7 . Novamente, os itens relativos ao tempero mereceram destaque.

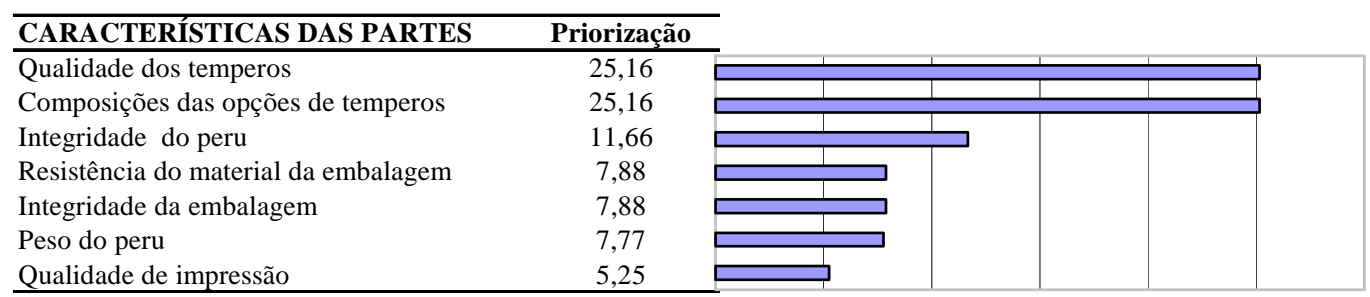

Figura 7 - Priorização das características das partes.

\subsubsection{Matriz dos Processos}

A matriz dos processos desdobra os processos de fabricação do produto, evidenciando as etapas associadas com as características de qualidade anteriormente destacadas, conforme apresentado na Figura 8. Objetiva-se identificar os processos críticos para a qualidade do produto, possibilitando a priorização dos processos a serem monitorados e/ou otimizados. 


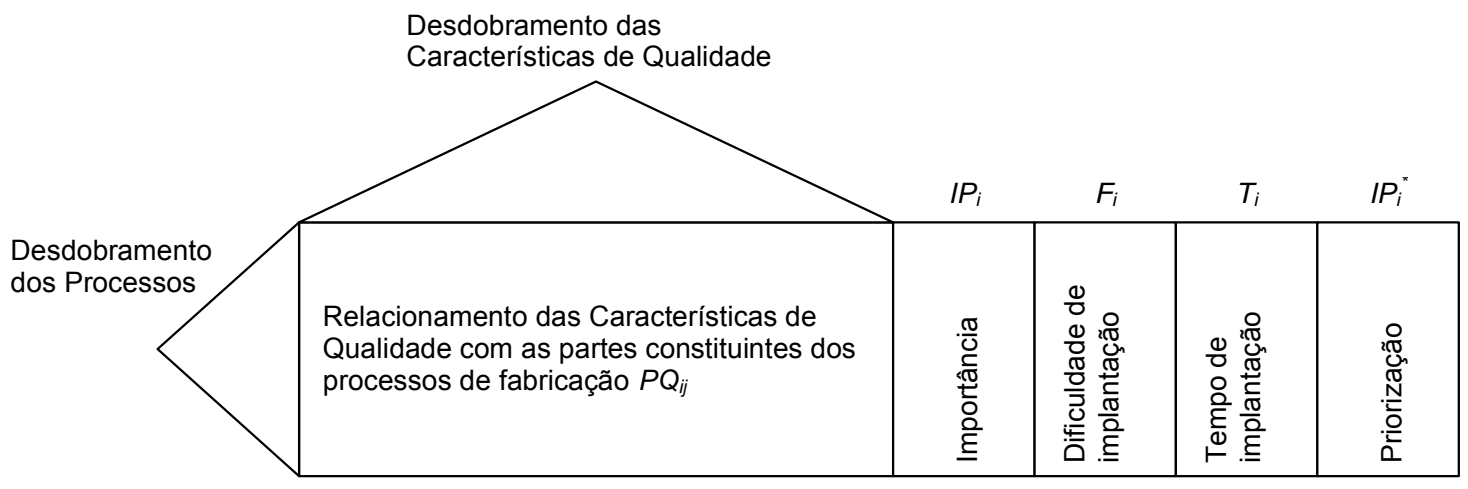

Figura 8 - Organização da Matriz do Processo. Adaptado de Ribeiro et al. (2001)

O relacionamento das Características de Qualidade $\left(\mathrm{IQj}^{*}\right)$ com as etapas do processo de fabricação (PQij) gera o índice da Importância dos Processos (IPi), de acordo com a equação (6). Este índice é novamente corrigido com base na dificuldade de implantação ( $\mathrm{Fi}$ ) e tempo necessário para aplicação de medidas corretivas (Ti), através da equação (7) e Tabela 4. As partes do processo de produção do Peru Natalino a serem priorizadas são apresentadas na Figura 9.

$\begin{aligned} I P_{i} & =\sum_{j=1}^{n} P Q_{i j} \times I Q_{j}^{*} \\ I P_{i}^{*} & =I P_{i} \times \sqrt{F_{i}} \times \sqrt{T_{i}}\end{aligned}$

PARTES DO PROCESSO

Injeção dos tipos de temperos

Desenvolvimento dos tipos de temperos

Elaboração dos tipos de temperos

Desenvolvimento do peru no campo

Abate da ave

Escaldagem e Depenagem da ave

Embalagem da ave

Evisceração da ave

Inspeção do produto final

Recebimento do peru

Recebimento e inspeção de embalagens

Inspeção da integridade da carcaça

Resfriamento da ave e absorção de água

Lavagem da carcaça

Expedição do produto

Armazenamento em câmaras de refrigeração

Figura 9 - Priorização das partes do processo.

Seguindo a tendência verificada nas matrizes anteriores, os processos relacionados aos temperos devem ser priorizados com o objetivo de alcançar a qualidade desejada. O processo de "injeção dos tipos de tempero" obteve destacada priorização por estar fortemente ligado ao sabor do peru (item prioritário de qualidade demanda), além de ser uma etapa de fácil e rápida alteração. 


\subsubsection{Matriz dos Parâmetros do Processo}

A análise do processo é concluída pela construção da Matriz dos Parâmetros do Processo, a qual utiliza a escala de intensidade (1-9) para quantificar a importância de cada parâmetro ajustável do processo com as partes do produto destacadas na Figura 6. A Figura 10 apresenta os principais parâmetros de processo a serem priorizados na elaboração do Peru Natalino (em razão do elevado número de parâmetros listados, apenas os seis mais importantes são listados nesta figura).

\begin{tabular}{lcc|}
\hline PARÂMETROS DO PROCESSO & Priorização \\
\hline Percentual de injeção de tempero/ave & 26,28 & \\
Quantidade de ração por lote/dia & 26,16 & \\
Tempo de desenvolvimento da ave no campo & 25,64 & \\
Tempo de desenvolvimento de tipos de temperos & 11,94 & \\
Quantidade de especiarias/1.000 litros de tempero & 11,45 & \\
Intensidade do choque & 11,30 \\
\hline
\end{tabular}

Figura 10 - Priorização dos parâmetros do processo.

A priorização do "Percentual de injeção de tempero por ave" é justificada pelo elevado valor de $\mathrm{IPi}^{*}$ procedente da Matriz de Processo, aliado a um alto valor atribuído a este parâmetro através da escala de intensidade. Os parâmetros "Quantidade de ração por lote por dia" e "Tempo de desenvolvimento da ave no campo" apresentaram posição destacada na escala de priorização por conta de sua influência sobre diversas etapas do processo, apesar dos $\mathrm{IPi}^{*} \mathrm{~s}$ para esses parâmetros terem se mostrado bastante inferiores quando comparados ao IPi* da "Injeção de tipos de temperos".

As etapas de processo e produto a serem priorizadas num plano de melhoria são então vinculadas aos recursos da empresa, de maneira a definir a responsabilidade de pessoal e disponibilidade de maquinário para efetivação de melhorias. Tal procedimento é viabilizado através da integração da Matriz dos Recursos aos resultados da análise de demanda do produto, descritos na seqüência.

\subsubsection{Matriz dos Recursos e Incorporação de Previsão de Demanda}

Nesta etapa, os modelos de previsão descritos na Seção 2.2 são aplicados a dados históricos de demanda do produto Peru Natalino, visando estimar níveis de consumo para o próximo período (2008). Tais níveis são convertidos em recursos produtivos necessários (maquinário e mão de obra) e então cruzados com os recursos existentes e disponíveis à produção. Na seqüência, especialistas de processo avaliam a relação entre tais recursos (demandados $\times$ disponíveis),codificando as necessidades de aquisição de novos maquinários e mão-de-obra através das escalas apresentadas na Tabela 5. A idéia é incorporar ajustes na Matriz de Recursos (explicada na seqüência), de modo a garantir a disponibilidade de maquinário, mão-de-obra e insumos para atender a demanda em termos qualitativos e quantitativos. Um exemplo do 
procedimento proposto é descrito na seqüência. Por conta de restrições impostas pela empresa, dados genéricos de demanda e capacidade produtiva ilustram a modelagem.

Dados históricos de demanda anual do produto Peru Natalino foram modelados através de Suavização Exponencial Simples (SES), Suavização Linear de Holt (SLH) e Box-Jenkis (BJ), utilizando-se o aplicativo Forescat Pro. O método SLH foi escolhido por conta de sua melhor aderência aos dados (avaliados através de coeficiente de determinação (R2) e soma dos quadrados dos resíduos), gerando uma estimativa de consumo de ES1 aves para o ano de 2008. A melhor aderência do método SLH aos dados da série histórica de demanda é devido ao fato da série temporal apresentar somente componentes de tendência e erro, não apresentando o componente de sazonalidade. A série temporal utilizada era composta pela demanda mensal do produto no mês de dezembro (8 anos de demanda), sendo desconsiderados os outros meses do ano devido à baixa/inexistente demanda (visto que o produto não é produzido fora da época de festas de final de ano). A estimativa de consumo ES1 foi então ajustada subjetivamente pela Força de Vendas da Empresa com informações sobre tendências de mercado, gerando uma estimativa de consumo ajustada ES2.

A empresa dispõe de duas injetoras de tempero, sendo que cada máquina possui uma capacidade de processamento de CP aves/dia. Por conta da necessidade de compartilhamento destas máquinas com outros produtos da empresa, a produção deve ser iniciada DD dias antes do encaminhamento do produto ao revendedor. A relação $E S_{2} / C P \cdot D D$ resulta em 2,4 , indicando que três injetoras são necessárias para efetivar a programação (ou seja, necessidade de aquisição de uma máquina extra, visto que não há possibilidade de terceirização). Esse cenário é então avaliado pela equipe de desenvolvimento, que atribui uma escala de ponderação 2 para a necessidade de aquisição de maquinário (Zj), de acordo com a Tabela 5.

A análise de capacidade produtiva descrita acima é efetivada para todos os recursos produtivos da empresa. $O$ ajuste dos recursos de mão-de-obra é realizado para cada profissional, com base no índice de ponderação Yj da Tabela 5. Aspectos ligados ao custo são abordados em índice próprio, apresentado na seqüência. É importante mencionar que não são considerados aspectos relativos à redução de equipamentos (ou demissão de funcionários) no caso de diminuição de demanda ou elevada capacidade de folga, o que justifica a omissão do valor 0,5 na Tabela 5.

\begin{tabular}{|c|c|c|c|}
\hline \multicolumn{2}{|c|}{$\begin{array}{c}\text { Necessidade de contratação com base na } \\
\text { demanda futura }\left(Y_{j}\right)\end{array}$} & \multicolumn{2}{|c|}{$\begin{array}{c}\text { Necessidade de aquisição de maquinário com } \\
\text { base na demanda futura }\left(Z_{j}\right)\end{array}$} \\
\hline Escala & Descrição & Escala & Descrição \\
\hline 2,0 & Alta & 2,0 & Alta \\
\hline 1,5 & Moderada & 1,5 & Moderada \\
\hline 1,0 & Baixa & 1,0 & Baixa \\
\hline
\end{tabular}

Os índices gerados pela inclusão dos aspectos de demanda futura são então integrados à Matriz de Recursos. Tendo-se em vista que os processos foram anteriormente vinculados às características de qualidade, é possível relacionar, de forma indireta, as características de qualidade aos recursos humanos e à infra-estrutura necessários à sua realização (Ribeiro et al., 2001). A estrutura da Matriz dos Recursos, acrescida dos índices associados à previsão de demanda, é apresentada na Figura 11. 


\begin{tabular}{|c|c|}
\hline $\begin{array}{l}\text { Desdobramento dos Recursos } \\
\text { Humanos }\end{array}$ & Desdobramento da Infra-Estrutura \\
\hline $\begin{array}{l}\text { Relacionamento dos Processos } \\
\text { com os itens de Recursos } \\
\text { Humanos } P R_{i j}\end{array}$ & $\begin{array}{l}\text { Relacionamento dos Processos } \\
\text { com os itens de Infra-estrutura } \\
P R_{i j}\end{array}$ \\
\hline Importância Técnica $I R_{j}$ & Importância Técnica $I R_{j}$ \\
\hline $\begin{array}{l}\text { Necessidade de contratação com } \\
\text { base na demanda futura } Y_{j}\end{array}$ & $\begin{array}{l}\text { Necessidade de aquisição de } \\
\text { maquinário com base na } \\
\text { demanda futura } Z_{j}\end{array}$ \\
\hline Custo $C_{j}$ & Custo $C_{j}$ \\
\hline Dificuldade de implantação $L_{j}$ & Dificuldade de implantação $L_{j}$ \\
\hline Priorização $I R_{i}^{*}$ & Priorização $I R_{j}{ }^{*}$ \\
\hline
\end{tabular}

Figura 11 - Organização da matriz dos recursos.

$\mathrm{Na}$ parte esquerda da matriz, definida como Matriz dos Recursos Humanos, são relacionadas as diversas funções dos trabalhadores da empresa às etapas do processo. A intensidade de cada cruzamento é estimada pela escala (1-9) e, através da equação (8), obtém-se o índice de importância dos recursos humanos (IRj). Este índice é então corrigido em duas frentes [através da equação (9)]: (i) levando-se em consideração dificuldade de implantação Fi (Tabela 4) e custos; e (ii) avaliando-se a capacidade atual de mão-de-obra frente à demanda futura estimada pelas ferramentas de previsão (Tabela 5). Aspectos ligados ao aprendizado de novos contratados podem ser inseridos no índice de dificuldade de implantação, enquanto que os custos de contratação e manutenção de pessoal são vinculados ao índice de ponderação para custos (Cj), o qual é facilmente construído nos moldes dos índices anteriores (onde 0,5 refere-se a custos altos e 2,0 a custos baixos). É importante salientar que a inclusão de mais de dois índices de correção requer a adequação da expressão matemática de forma a garantir que a escala de correção esteja contida no intervalo 0,5 e 2 [veja exemplo da equação (9), na qual a raiz cúbica é aplicada por conta da utilização de três índices de correção].

$$
\begin{aligned}
& I R_{j}=\sum_{i=1}^{n} P R_{i j} \times I P_{i}^{*} \\
& I R_{j}^{*}=I R_{j} \times \sqrt[3]{F_{j}} \times \sqrt[3]{C_{j}} \times \sqrt[3]{Y_{j}}
\end{aligned}
$$

A priorização dos recursos humanos corrigida (IRj*) é apresentada na Figura 12. 


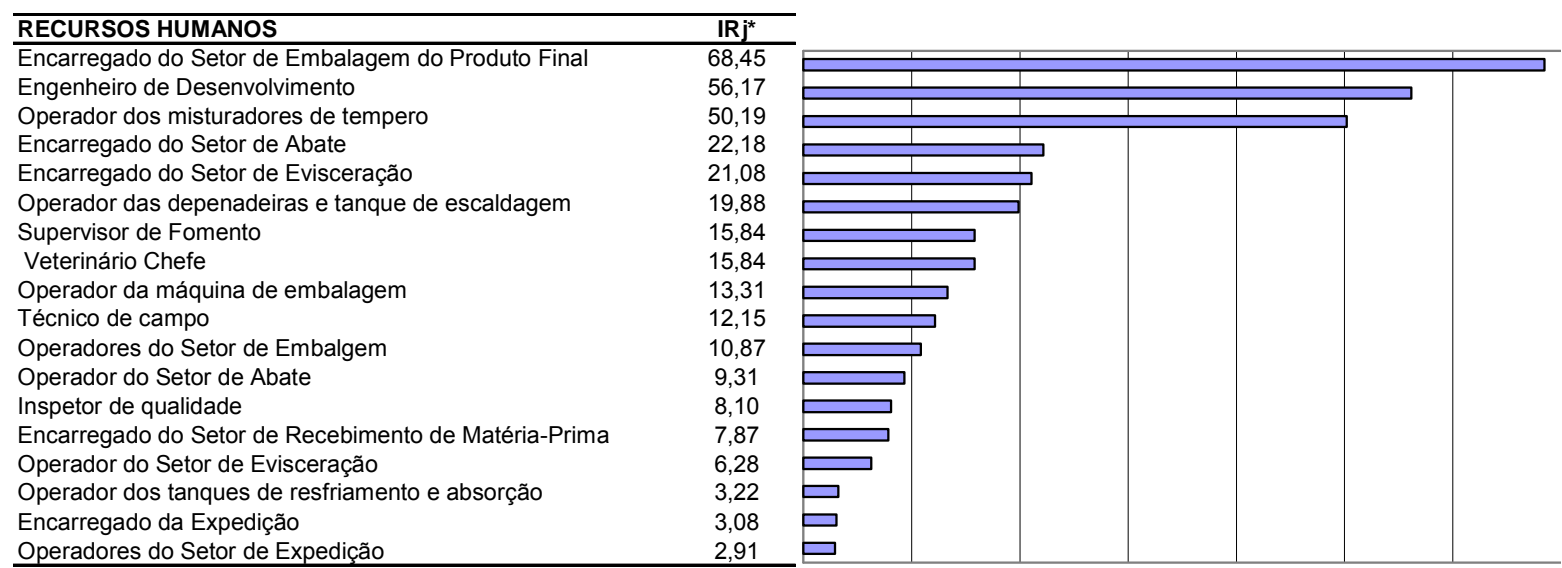

Figura 12 - Priorização dos Recursos Humanos.

O encarregado do Setor de Embalagem do Produto Final assume grande importância em virtude da demanda por um produto com aparência agradável (item de qualidade demandada pelo consumidor, conforme Figura 2). Engenheiro de Desenvolvimento e Operador dos misturadores de tempero apresentam priorização destacada por estarem intimamente ligados aos processos de desenvolvimento e preparação dos temperos, área essa continuamente apontada como prioritária pelas matrizes de produto e processo. A elevada priorização dos três profissionais acima listados também é decorrente da limitada disponibilidade de horas de trabalho dos mesmos frente à demanda futura. A contratação e treinamento de tais profissionais passam a ser fundamental para a obtenção de um produto equalizado com as demandas dos consumidores.

De maneira análoga, construiu-se a Matriz de Itens de Infra-Estrutura (parte direita da matriz apresentada na Figura 11), avaliando-se a importância de máquinas e insumos utilizados no processo. Neste caso, o índice IRj foi corrigido com base na equação (9), substituindo-se a escala de ponderação Yj por Zj (Tabela 5). A escala de custos considerou aspectos de aquisição de maquinário e manutenção, entre outros.

Os resultados desta priorização são apresentados na Figura 13. Insumos relativos à sala de elaboração de tempero e injetora apresentaram alta priorização (i) por estarem intimamente ligados aos itens de tempero (seguindo a tendência das priorizações anteriores), (ii) e por não apresentarem capacidade produtiva suficiente para atender a demanda futura, indicando a necessidade de aquisição de equipamentos para execução das suas operações. 


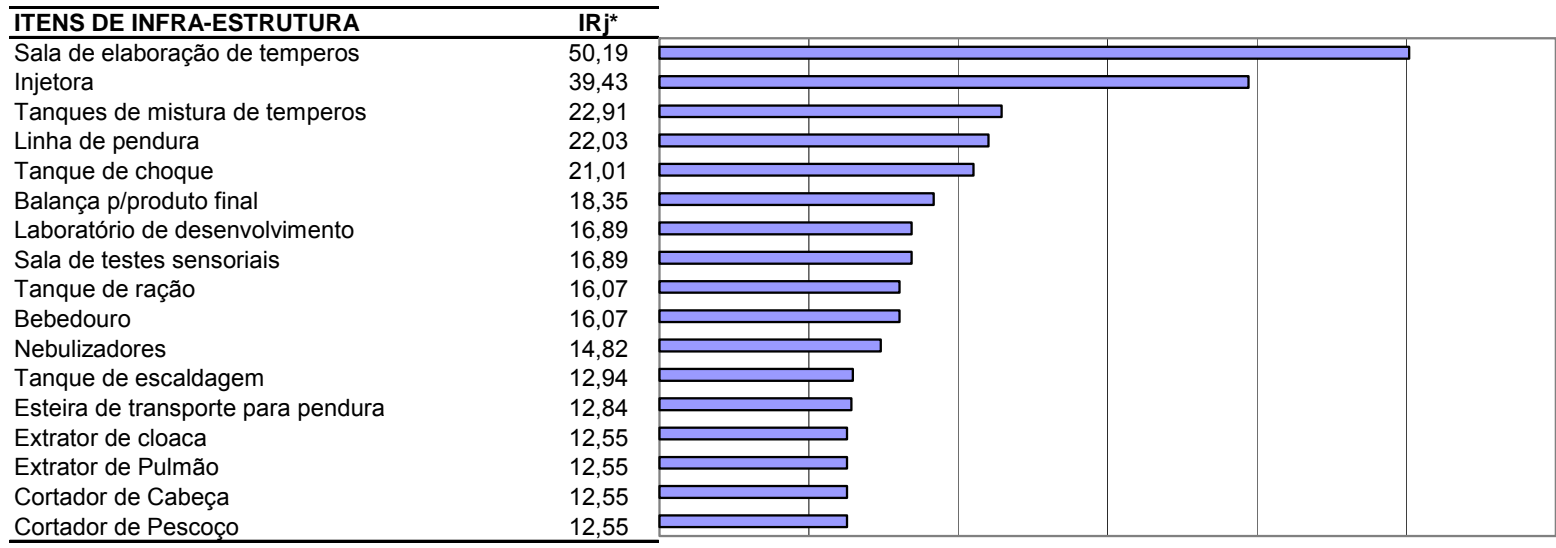

Figura 13 - Priorização dos itens de infra-estrutura.

A seção seguinte traz propostas práticas de melhorias no processo produtivo em análise, com base nos resultados gerados pela metodologia proposta e parecer de especialistas.

\section{Planejamento da Qualidade}

O planejamento de melhorias do sistema produtivo em estudo foi estruturado em quatro frentes: (i) melhoria no processo, (ii) melhoria das partes, (iii) melhoria das características de qualidade (especificações), e (iv) melhoria dos recursos, sendo resumidamente descrito nas seções seguintes. Vale acrescentar que ações corretivas efetuadas em determinado item eventualmente reforçam ações de melhoria em outros.

\subsection{Plano de Melhoria no Processo}

Com base na Matriz de Processo, priorizaram-se os itens de "Desenvolvimento do peru no campo" e "Desenvolvimento, elaboração e injeção dos tipos de tempero". A ação de melhoria para desenvolvimento do peru no campo buscará um tempo ótimo de permanência das aves no campo, aliado a um cronograma de alimentação adequado. Os quesitos relacionados ao tempero serão aprimorados através do desenvolvimento de novas opções de tempero, instalação de máquinas dosadoras de ingredientes e aquisição de misturadores mais eficientes para atender a demanda prevista. Também objetiva-se monitorar o processo de injeção de tempero por intermédio de amostragem do produto final no início de cada turno. 
Com base na matriz do produto, priorizaram-se as partes "Tempero" e "Peru inteiro". A ação de melhoria para o tempero consistirá na implantação de indicadores de qualidade para fornecedores de ingredientes. A implantação de um sistema preventivo de controle como o método de Análise de Perigos e Pontos Críticos de Controle (Hazard Analysis Critical Control Points - HACCP) será avaliada, visando eliminar a possibilidade de contaminações de natureza biológica ou química.

Melhorias voltadas ao peru inteiro avaliarão as condições de transporte da ave do aviário até o frigorífico (dimensões dos contenedores utilizados para transporte das aves e rotas dos caminhões, entre outros), e na manipulação das aves no setor de abate (treinamento dos operadores).

\subsection{Plano de Melhoria das Especificações}

Serão avaliados os três itens priorizados da matriz da qualidade das especificações: (i) Número de opções de tempero, (ii) Percentual de injeção de ingredientes por unidade, e (iii) Tempo de criação da ave no campo por lote.

Variedades adicionais de tempero serão desenvolvidas e submetidas à aprovação sensorial por especialistas. O percentual de injeção de ingredientes por unidade será aprimorado através da otimização das dosagens de cada tipo de tempero a ser injetado, além do monitoramento da dosagem liberada pelas injetoras. Melhorias em relação ao tempo de criação da ave no campo serão baseadas no fornecimento de assistência técnica (veterinários da empresa) aos criadores, além dos itens especificados na Seção 4.1.

\subsection{Plano de Melhoria dos Recursos}

Com base nos resultados da matriz de recursos humanos, os profissionais "Operador dos misturadores de tempero", "Encarregado do setor de embalagem do produto final" e "Engenheiro de desenvolvimento" devem ser priorizados em planos de melhorias. As ações incluem a contratação imediata de um profissional adicional para cada área e inclusão dos mesmos em programas de treinamento oferecidos pela empresa, de acordo com sua especialidade.

Em relação aos recursos de Infra-Estrutura, priorizaram-se os componentes "Sala de elaboração de temperos" e "Máquina injetora". A sala será remodelada pela instalação de prateleiras com identificação clara das especiarias e disponibilização de painéis com informações quantitativas para cada tempero. A aquisição de uma nova injetora (recurso identificado como gargalo frente à demanda futura prevista), bem como a manutenção preventiva das injetoras existentes, evitará o entupimento das agulhas injetoras e filtro, garantindo a correta injeção de tempero na ave. 


\title{
5 CONCLUSÃO
}

Este artigo apresentou uma proposta de integração das matrizes do QFD a um processo de Previsão de Demanda de um produto, visando incorporar ao mesmo alterações baseadas nas exigências do cliente e promover ajustes na capacidade produtiva frente à demanda futura.

O desdobramento das matrizes mostrou-se eficiente na identificação de parâmetros de processo, produto e recursos a serem priorizados na adoção de melhorias. Os resultados sinalizaram a necessidade de concentração de esforços no aprimoramento das etapas associadas ao tempero, levando à obtenção de um produto equalizado com as exigências do consumidor em termos de maior variedade dos tipos de tempero e carne mais saborosa.

A reorganização das matrizes do QFD através da inclusão de técnicas de previsão de demanda auxiliou na identificação dos recursos tidos como gargalos para o atendimento das demandas priorizadas no QFD. Recursos associados à elaboração e injeção de tempero devem ser adquiridos, enquanto que profissionais associados ao tempero, desenvolvimento de produto e de embalagem devem ser contratados.

Por fim, salienta-se que o uso integrado destas técnicas permite à equipe de desenvolvimento uma visão globalizada ao conduzir aprimoramentos nos produtos. Para ilustrar o método, apresentou-se o estudo de um produto do setor alimentício.

\begin{abstract}
Quality Function Deployment (QFD) has been widely employed to convert customers' expectations into precise product and process specifications. Features prioritized by QFD, however, might not be successfully improved in case the required resources are not promptly available in the production system. This paper presents a detailed description of QFD steps and their integration with forecasting models to improve the sensoriy features of a food product. QFD reveals customers' most valued perception features, while forecasting models adjust resources availability in order to execute the prioritized features according to product demand variations. The proposed approach led to improvement procedures based on the prioritized features.
\end{abstract}

Keywords: QFD. Forecasting. Food process. 


\section{REFERÊNCIAS}

AKAO Y. Quality function deployment: integrating customer requirements into product design. Cambridge: Productivity Press, 1992.

ARCHER, B. Forecasting demand: quantitative and intuitive techniques. International Journal of Tourism Management, Netherlands, v.1, n.1, p. 5-12, 1980.

ARMSTRONG, J. Selecting forecasting methods. In: ARMSTRONG, J. Principles of Forecasting: a Handbook for Researchers and Practitioners. Boston: Kluwer Academic Publishers, 2001.

BENNER, M.; LINNEMANN, A.; JONGEN, W.; FOLSTAR, P. Quality function deployment (QFD) - can it be used to develop food products?, Food Quality and Preference, Netherlands, v. 14, p. 327-339, 2003.

BLATTBERG, R. C.; HOCH, S. J. Database models and managerial intuition: $50 \%$ model $+50 \%$ manager. Management Science, Hanover, v. 36, n. 8, p. 887-899, 1990.

CHAMBERS, J. C.; MULLICK, S. K.; SMITH, D. D. How to choose the right forecasting technique. Harvard Business Review, Boston, v. 49, July-August, p. 45-57, 1971.

CHAN, L.; WU, M. A systematic approach to quality function deployment with a full illustrative example. Omega, Netherlands,v. 33, n.2, p. 119-139, 2005.

CLEMEN, R. T. Combining forecasts: A review and annotated bibliography.

International Journal of Forecasting, Netherlands,v. 5, n. 4, p. 559-583, 1989.

DA SILVEIRA, G.; BORESTEIN, D.; FOGLIATTO, F. S. Mass customization: Literature review and research directions. International Journal of Production Economics, New York, v. 72, p. 1-13, 2001.

DE RON, A. J. Sustainable production: the ultimate result of a continuous improvement. International Journal of Production Economics, New York, v. 56-57, p. 99-110, 1998.

DIKMEN, I.; BIRGONUL, M.; KIZILTAS, S. Strategic use of quality function deployment (QFD) in the construction industry. Building and Environment, Netherlands, v. 40, p. 245-255, 2005.

ELSAYED, E.; BOUCHER, T. Analysis and control of production systems, 2. ed., New Jersey: Prentice-Hall, 1994.

FOGLIATTO, F. S.; DA SILVEIRA; G.J., ROYER, R. Feasibility index for mass customization. In: 2001 World Congress on Mass Customization and Personalization, CD-ROM, 2001, Hong Kong, 1 CD ROM. 
GEORGOFF, D. M.; MURDICK, R. G. Manager's guide to forecasting. Harvard Business Review, Boston, v. 64, n. 1, p. 110-120, Jan/Feb 1986.

GOODWIN, P. Integrating management judgment and statistical methods to improve short-term forecasts. Omega, Netherlands, v. 30, n. 2, p. 127-135, 2002.

Improving the voluntary integration of statistical forecasts and judgment. International Journal of Forecasting, Netherlands, v. 16, n. 1, p. 85-99, 2000.

GOVERS, C.P.M. What and how about quality function deployment (QFD).

International Journal of Production Economics, New York, V.46-47, p. 575-585, 1996.

GOVERS, C.P.M. QFD not just a tool but a way of quality management. International Journal of Production Economics, New York, v. 69, p. 151-159, 2001.

HANSEN, T. Quality in the marketplace: a theoretical and empirical investigation. European Management Journal, Netherlands, v. 19, n. 2, p. 203-211, 2001.

HARI, A.; KASSER, J.; WEISS, M. How lessons learned from using QFD led to the evolution of a process for creating quality requirements for complex systems. Systems Engineering, Massachusetts, v.10, n.1, 45-63, 2007.

JADGEV, H.; BRADLEY, P.; MOLLOY, O. A QFD based performance measurement tool. Computers in Industry, Netherlands, v. 33, p. 357-366, 1997.

$\mathrm{KAHN}, \mathrm{K}$. An exploratory investigation of new product forecasting practices. The Journal of Product Innovation Management, Massachusetts, v. 19, n. 2, p. 133-143, 2002.

KOTLER, P. Marketing management: Analysis, planning, implementation, and control. New Jersey: Prentice-Hall, 1991.

KWONG, C.; CHEN, Y.; BAI, H.; CHAN, D. A methodology for determining aggregated importance of engineering characteristics in QFD. Computers \& Industrial Engineering, Netherlands, v. 53, n. 4, 667-679, 2007.

LINDBERG, E; ZACKRISSON, U. Deciding about the uncertain: The use of forecasts as an aid to decision-making. Scandinavian Journal of Management, Netherlands, v. 7, n. 4, p. 271-283, 1991.

LEMOS, F. O. Metodologia para seleção de métodos de previsão de demanda. Porto Alegre: UFRGS, 2006. 172p. Dissertação (Mestrado em Engenharia de Produção), Departamento de Engenharia de Produção e Transportes, Universidade Federal do Rio Grande do Sul, 2006. 
LOWE, A; RIDGWAY, K.; ATKINSON, H. QFD in new production technology evaluation, International. Journal of Production Economics, New York, v. 67, p. 103-112, 2000.

LYNN, G.; SCHNAARS, S.; SKOV, R. Survey of new product forecasting practices in industrial high technology and low technology businesses. Industrial Marketing Management, Netherlands, v. 28, n. 6, p. 565-571, 1999.

MENTZER, J. T.; COX, Jr. J. E. Familiarity, application, and performance of sales forecasting techniques. Journal of Forecasting, Massachusetts, v. 3, n.1, p. 27-36, 1984.

MENTZER, J. T.; GOMES, R. Evaluating a decision support forecasting system. Industrial Marketing Management, Netherlands, v. 18, n. 4, p. 313 -323, 1989.

MOON, M; MENTZER, J.; SMITH, C.; GARVER, M. Seven keys to better forecasting. Business Horizons, Netherlands, v. 41, n. 5, p. 44-52, 1998.

MONTGOMERY, D.; JOHNSON, L.; GARDINER, J. Forecasting and time series analysis. New York: McGraw-Hill, 1990.

NI, M.; XU, X.; DENG, S. Extended QFD and data-mining-based methods for supplier selection in mass customization. International Journal of Computer Integrated Manufacturing, London, v. 20, n. 2-3, 280-291, 2007.

POEL, I. Methodological problems in QFD and directions for future development. Research in Engineering Design, New York, v. 18, n. 1, 21-36, 2007.

PRAMOD, V.; DEVADASAN, S.; MUTHU, S.; JAGATHYRAJ, V.; MOORTHY, G. Integrating TPM and QFD for improving quality in maintenance engineering. Journal of Quality in Maintenance Engineering, London, v. 12, n. 2, 150-171, 2006.

RIBEIRO, J.; ECHEVESTE, M.; DANILEVICZ, A. A utilização do QFD na otimização de produtos, processos e serviços. Série Monográfica Qualidade, FEENG-UFRGS, 2001.

RINGUEST, J. L.; TANG, K. Simple rules for combining forecasts: Some empirical results. Socio-Economic Planning Science, Netherlands, v. 21, n. 14, p. 239-243, 1987.

SAKAO, T. A QFD-centered design methodology for environmentally conscious product design, International Journal of Production Research, London, v. 45, n. 18-19, 41434162, 2007.

SANDERS, N. R.; MANRODT, K. Forecasting practices in US corporations: Survey results. Interfaces, Massachusetts, v. 24, n. 2, p. 92-100, 1994.

SANDERS, N. R.; RITZMAN, L. P. Bringing judgment into combination forecasts. Journal of Operations Management, Netherlands, v. 13, n. 4, p. 311-321, 1995. 
SPEDDING, T; CHAN, K. Forecasting demand and inventory management using bayesian time series. Integrated Manufacturing Systems, London, v. 11, n. 5, p. 331339, 2000.

SULLIVAN, L. P. Quality function deployment. Quality Progress, Netherlands, v. 19, n.6, p. 39-50, 1986.

THOMAS, R. J. Forecasting new product market potential: Combining multiple methods. The Journal of Product Innovation Management, Massachusetts, v. 4, n. 2, p. 109119, 1987.

WANG, H.; HONG, W. An integrated service strategy by QFD approach: a case of a telecom company in Taiwan. International Journal of Management and Decision Making, United Kingdom, v. 8, n. 2-4, 251-267, 2007.

WEBBY, R.; O'CONNOR, M. Judgmental and statistical time series forecasting: a Review of the literature. International Journal of Forecasting, Netherlands, v. 12, n. 1, p. 91-118, 1996.

WINKLHOFER, H.; DIAMANTOPOULOS, A.; WITT, S. Forecasting practice: a Review of the empirical literature and an agenda for future research. International Journal of Forecasting, Netherlands, v. 12, n. 2, p. 193-221, 1996.

WRIGHT, G.; LAWRENCE, M.; COLLOPY, F. The Role and validity of judgment in forecasting. International Journal of Forecasting, Netherlands, v. 12, n. 1, p. 1-8, 1996. 


\section{Anexo A - Questionário quantitativo (fechado) utilizado no estudo}

\begin{tabular}{|l|l|}
\hline $\begin{array}{l}\text { Favor não preencher este quadro } \\
\text { Num. do questionário }\end{array}$ \\
\hline $\begin{array}{l}\text { Estamos realizando uma pesquisa a respeito do que você, como cliente, valoriza na hora da compra ao escolher o peru temperado para consumo nas festas de fim de ano.Sua opinião é importante } \\
\text { para nós! Desde já agradecemos a sua contribuição a essa pesquisa e prometemos sigilo absoluto desses dados. Obrigado por colaborar! }\end{array}$ \\
\hline Aqui, queremos que você indique com um "X" a nota que expressa o grau de importância para os itens que aparecem à esquerda. \\
\hline
\end{tabular}

1. Quanto aos aspectos visuais do peru, o mais importante é:

\begin{tabular}{|c|c|c|c|c|c|c|c|c|c|c|}
\hline \multirow{5}{*}{$\begin{array}{r}\text { Boa aparência da embalagem } \\
\text { m conformidade com o produto } \\
\text { Boa aparência do produto } \\
\text { partes quebradas ou separadas }\end{array}$} & \multicolumn{2}{|c|}{$\begin{array}{c}\text { Pouco } \\
\text { importante }\end{array}$} & \multicolumn{6}{|c|}{ Regular } & \multicolumn{2}{|c|}{$\begin{array}{c}\text { Muito } \\
\text { importante }\end{array}$} \\
\hline & 1 & 2 & 3 & 4 & 5 & 6 & 7 & 8 & 9 & 10 \\
\hline & 1 & 2 & 3 & 4 & 5 & $\overline{6}$ & 7 & 8 & 9 & 10 \\
\hline & 1 & 2 & 3 & 4 & 5 & 6 & 7 & 8 & 9 & 10 \\
\hline & 1 & 2 & 3 & 4 & 5 & 6 & 7 & 8 & 9 & 10 \\
\hline
\end{tabular}

2. Quanto ao tamanho do peru, o mais importante é:

\begin{tabular}{|c|c|c|c|c|c|c|c|c|c|c|}
\hline \multirow{4}{*}{$\begin{array}{l}\text { Variedade do tamanho } \\
\text { Maior quantidade de carne branca } \\
\text { Bom rendimento do produto }\end{array}$} & \multicolumn{2}{|c|}{$\begin{array}{c}\text { Pouco } \\
\text { importante }\end{array}$} & \multicolumn{6}{|c|}{ Regular } & \multicolumn{2}{|c|}{$\begin{array}{c}\text { Muito } \\
\text { importante }\end{array}$} \\
\hline & 1 & 2 & 3 & 4 & 5 & 6 & 7 & 8 & 9 & 10 \\
\hline & 1 & 2 & 3 & 4 & 5 & 6 & 7 & 8 & 9 & 10 \\
\hline & 1 & 2 & 3 & 4 & 5 & 6 & 7 & 8 & 9 & 10 \\
\hline
\end{tabular}

3. Quanto ao sabor do peru, o mais importante é:

\begin{tabular}{|c|c|c|c|c|c|c|c|c|c|c|}
\hline \multirow{3}{*}{ Carne com boa consistência } & \multicolumn{2}{|c|}{$\begin{array}{c}\text { Pouco } \\
\text { importante }\end{array}$} & \multicolumn{6}{|c|}{ Regular } & \multicolumn{2}{|c|}{$\begin{array}{c}\text { Muito } \\
\text { importante }\end{array}$} \\
\hline & 1 & 2 & 3 & 4 & 5 & 6 & 7 & 8 & 9 & 10 \\
\hline & 1 & 2 & 3 & 4 & 5 & $\overline{6}$ & $\overline{7}$ & 8 & 9 & 10 \\
\hline Carne mais saborosa & 1 & 2 & 3 & 4 & 5 & $\overline{6}$ & $\overline{7}$ & 8 & 9 & 10 \\
\hline Variedade de tipos de temperos & 1 & 2 & 3 & 4 & 5 & 6 & 7 & 8 & $\overline{9}$ & 10 \\
\hline
\end{tabular}

4. Quanto ao preparo do peru, o mais importante é

\begin{tabular}{|l|l|l|l|l|l|l|l|l|l|}
\hline $\begin{array}{c}\text { Pouco } \\
\text { importante }\end{array}$ \\
\hline 1 & 2 & 3 & 4 & 5 & 6 & 7 & 8 & 9 & 10 \\
\hline 1 & 2 & 3 & 4 & 5 & 6 & 7 & 8 & 9 & 10 \\
\hline 1 & 2 & 3 & 4 & 5 & 6 & 7 & 8 & 9 & 10 \\
\hline 1 & 2 & 3 & 4 & 5 & 6 & 7 & 8 & 9 & 10 \\
\hline
\end{tabular}

5. Enumere de 1 (mais importante) a 4 (menos importante) o que você julga essencial para a aquisição e consumo de peru nas festas de final de ano, (não vale usar o mesmo número mais de 1 vez).

Ter um bom aspecto visua

$($ )

Ter um sabor agradável

$($ )

Ter um tamanho adequado

( )

Apresentar praticidade no preparo

( ) 
Anexo B - Matriz de Qualidade da Seção 3.2.1

\begin{tabular}{|c|c|c|c|c|c|c|c|c|c|c|c|c|c|c|c|c|c|c|}
\hline & 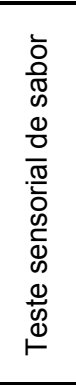 & 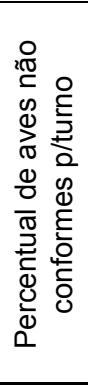 & 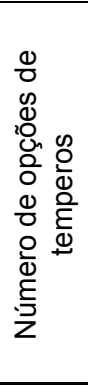 & 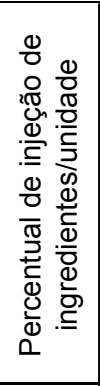 & 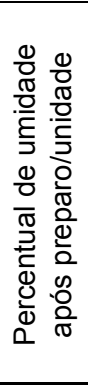 & 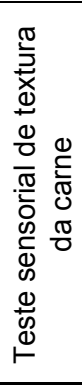 & 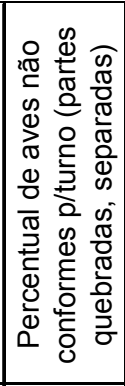 & 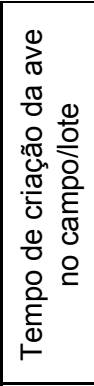 & 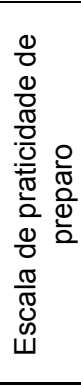 & 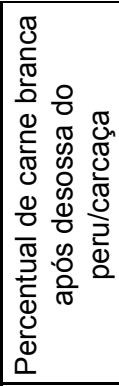 & 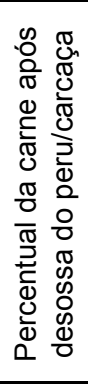 & 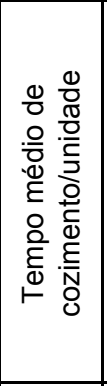 & 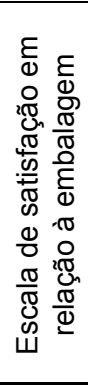 & 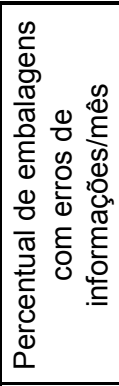 & $I D i$ & $\mathrm{Ei}$ & Mi & $I D i^{*}$ \\
\hline Carne mais saborosa & 9 & 3 & 6 & 9 & 6 & 3 & & 3 & & & & 3 & & & 8.7 & 1.5 & 2 & 15.1 \\
\hline Boa aparência do produto & & 9 & & & & & 9 & 3 & & & & & & & 7.1 & 1.5 & 2 & 12.3 \\
\hline Variedade de tipos de temperos & 9 & & 9 & 9 & & & & & & & & & & & 6.7 & 1.5 & 2 & 11.6 \\
\hline Carne tenra e suculenta & 6 & 3 & 3 & 3 & 9 & 6 & & 3 & & & & 6 & & & 8.4 & 1 & 1.5 & 10.3 \\
\hline Carne com boa consistência & 3 & 9 & 3 & 3 & 6 & 9 & & 6 & & & & 6 & & & 7.8 & 1 & 1.5 & 9.6 \\
\hline $\begin{array}{l}\text { Produtos sem partes quebradas ou } \\
\text { separadas }\end{array}$ & & & & & & & 9 & & 1 & & & & & & 6.7 & 1 & 2 & 9.5 \\
\hline Variedade do tamanho & & & & & & & & 9 & 6 & 3 & 3 & & & & 5.6 & 1.5 & 1.5 & 8.4 \\
\hline $\begin{array}{l}\text { Praticidade no preparo e/ou } \\
\text { consumo }\end{array}$ & & & 3 & 3 & & & & 1 & 9 & & & 6 & 6 & 3 & 6.8 & 1 & 1.5 & 8.3 \\
\hline Maior quantidade de carne branca & & 3 & & & & & & 3 & & 9 & 6 & & & & 6.3 & 1 & 1.5 & 7.7 \\
\hline Bom rendimento do produto & & 3 & & & & & & 6 & & 6 & 9 & & & & 6.4 & 1 & 1.5 & 7.8 \\
\hline $\begin{array}{l}\text { Redução do tempo de cozimento } \\
\text { e/ou preparo }\end{array}$ & 3 & & 1 & 1 & 1 & & & 1 & 6 & & & 9 & & & 6 & 1 & 1.5 & 7.3 \\
\hline Boa aparência da embalagem & & & & & & & & & & & & & 9 & 6 & 5.9 & 1 & 1.5 & 7.2 \\
\hline $\begin{array}{l}\text { Inf. contidas na embalagem em } \\
\text { conformidade com o produto }\end{array}$ & & & & & & & & & & & & & 6 & 9 & 6.1 & 1 & 1 & 6.1 \\
\hline Especificações atuais & 7 & $1 \%$ & 2 & $<=20 \%$ & $15 \%$ & 8 & $5 \%$ & 70 dias & 6 & $30 \%$ & $70 \%$ & 1h30min & 9 & $0.50 \%$ & & & & \\
\hline & 35.25 & 31.94 & 28.67 & 33.19 & 24.77 & 19.29 & 19.60 & 33.17 & 17.89 & 14.17 & 14.20 & 28.04 & 15.16 & 12.32 & & & & \\
\hline Dificuldade de atuação & 1.5 & 1 & 2 & 2 & 1 & 1 & 1.5 & 2 & 1.5 & 0.5 & 1 & 1.5 & 2 & 1.5 & & & & \\
\hline Análise competitiva & 1 & 1 & 1.5 & 1 & 1.5 & 1.5 & 1 & 1 & 1 & 1 & 1 & 1 & 1.5 & 1 & & & & \\
\hline $\mid \mathrm{IQj} \mathrm{j}^{*}$ & 43.2 & 31.9 & 49.7 & 46.9 & 30.3 & 23.6 & 24.0 & 46.9 & 21.9 & 10.0 & 14.2 & 34.3 & 26.3 & 15.1 & & & & \\
\hline
\end{tabular}

